\title{
New tools for high reliability healthcare
}

\section{Michael Shabot ${ }^{1,2}$}

\begin{abstract}
${ }^{1}$ Memorial Hermann Health System, Houston, Texas, USA ${ }^{2}$ School of Public Health and School of Biomedical Informatics, The University of Texas at Houston, Houston, Texas, USA
\end{abstract}

\section{Correspondence to}

Dr M Michael Shabot, Memorial Hermann Health System, 929 Gessner Road, Suite 2700, Houston, TX 77024, USA; michael.shabot@ memorialhermann.org

Received 17 August 2014 Accepted 12 May 2015

\section{SLinked}

- http://dx.doi.org/10.1136/ bmjqs-2014-003484

- http://dx.doi.org/10.1136/ bmjqs-2014-003482

- http://dx.doi.org/10.1136/ bmjqs-2014-003483

\section{CrossMark}

To cite: Shabot MM. BMJ Qual Saf 2015;24:423-424.
Both lay and scientific literature confirm that preventable medical errors remain a major source of morbidity and mortality in US hospitals, responsible for upwards of 400000 hospital deaths per year. ${ }^{1}$ Over the past decade, Patel and colleagues have carefully documented the reasons medical errors occur, with special appreciation for the role of complexity in clinical situations. ${ }^{2}{ }^{3}$ Due to that complexity, and in recognition of the fallibility of human care, the issue quickly becomes how to mitigate errors before patients are adversely affected. It should be noted that to help ensure safe care, medical institutions rely on peer review of physicians, nurses, pharmacists and other care providers to administer education and/or penalties, up to and including dismissal from the staff. However, peer review occurs after an adverse event has occurred, and after a patient has been injured or worse. Thus, peer review cannot serve an ideal mechanism to prevent harm.

In the absence of human perfection, how can patient harm be prevented? Health information technology (HIT) has been shown to play a protective role by providing context-sensitive information displays, computerised provider order entry, bar code medication administration and automated real-time warnings and alerts. ${ }^{4}$ Conversely, HIT systems have been shown to significantly alter care processes and introduce new types of errors, thus adding to clinical complexity rather than mitigating it. ${ }^{5}$ Like humans, HIT systems are not perfectible.

Patel and colleagues advocate realworld clinical simulation as a method for care providers to appreciate, detect and correct errors in a safe environment. ${ }^{6}$ Simulation training is considered crucial in high-reliability organisations (HROs) such as commercial aviation, naval aviation, air traffic control and nuclear power. The rationale for simulation is to introduce anomalies, errors and system failures for human operators to experience, mitigate, control and learn from in a safe environment without human lives at stake. Thus, the experience and learning from a simulation exercise is in recovery from errors or system failures. Clinical learning through error generation, as advocated by Patel, is a powerful tool that has been little used in medical training or ongoing education. Simulation can provide the complexity, interruptions, time pressure and information overload that is representative of the real-world clinical environment. Since care providers operate with actual or virtual teams, clinical simulation needs to include other team members to fully parallel the clinical experience.

High reliability is a worthy and reasonable goal for healthcare, considering that the 400000 preventable US hospital deaths per year are equivalent to six fully loaded Boeing 737 aircraft crashing everyday, with total loss of life. HROs identify potential process defects and correct them to avoid the consequences of errors. ${ }^{7}$ HROs also create a culture in which safety is the core value, rather than expediency or other values. Adoption of a culture of safety, careful implementation of HIT, robust process improvement and clinical simulation can produce a healthcare environment in which inevitable errors and systematic failures do not reach patients and the need for peer review becomes rare.

\section{Competing interests None declared.}

Provenance and peer review Not commissioned; internally peer reviewed.

\section{REFERENCES}

1 James JT. A new, evidence-based estimate of patient harms associated with hospital care. J Patient Saf 2013;9:122-8. 


\section{Editorial}

2 Kannampallil TG, Schauer GF, Cohen T, et al. Considering complexity in healthcare systems. J Biomed Inform 2011;44:943-7.

3 Kahol K, Vankipuram M, Patel VL, et al. Deviations from protocol in a complex trauma environment: errors or innovations? J Biomed Inform 2011;44:425-31.

4 Bates DW, Cohen M, Leape LL, et al. Reducing the frequency of errors in medicine. J Am Med Inform Assoc 2001;8: 299-308.
5 Patel VL, Kannampallil T, Shortliffe EH. Role of cognition in generating and mitigating clinical errors. BMJ Qual Saf 2015;24:468-74.

6 Sittig DF, Ash JS, Osheroff JA, et al. Lessons from 'Unexpected increased mortality after implementation of a commercially sold computerized physician order entry system'. Pediatrics 2006;118:797-801.

7 Chassin MR, Loeb JM. The ongoing quality improvement journey: next stop, high reliability. Health Aff 2011;30:559-68. 